\title{
Evaluation of asymmetric poly(vinyl alcohol) membranes for use in artificial islets
}

\author{
Tai-Horng Young*, Nan-Kuang Yao ${ }^{\dagger}$, Rong-Fu Chang ${ }^{\ddagger}$ and \\ Leo-Wang Chen ${ }^{\ddagger}$ \\ ${ }^{*}$ Center for Biomedical Engineering, College of Medicine; ${ }^{\dagger}$ Department of Electrical Engineering, College of \\ Engineering; ${ }^{\ddagger}$ Department of Chemical Engineering, College of Engineering; National Taiwan University, Taipei, \\ Taiwan, R.O.C.
}

\begin{abstract}
Islets of Langerhans surrounded by a semipermeable membrane to prevent the host immunosystem is a potential way to treat type I diabetes mellitus. In this study, a series of poly (vinyl alcohol) membranes were formed by adding polyethylene glycols to create pores in the skin layer. The permeability study showed the skin layer structure had an influence on the diffusion of low molecular weight glucose, vitamin B12 and insulin. The mass transfer coefficient was improved from $1.04 \times 10^{-4}$ to $2.16 \times 10^{-4} \mathrm{~cm} /$ $\mathrm{sec}$ for glucose, from $2.84 \times 10^{-5}$ to $8.36 \times 10^{-5} \mathrm{~cm} / \mathrm{sec}$ for vitamin B12 and from $1.45 \times 10^{-6}$ to $4.15 \times 10^{-6} \mathrm{~cm} / \mathrm{sec}$ for insulin, whereas the passage of immunoglobulin $\mathrm{G}$ was completely prevented, indicating that these membranes could be effective in protecting islets from immunorejection. Thus such a membrane is an alternative potential material for artificial islets. In addition, we examined the insulin secretory response of islets separated by a poly(vinyl alcohol) membrane. We found that the insulinsecretion rate is relatively rapid compared to the permeation rate of insulin; thus, the process of the artificial islets is insulin-diffusion-controlled. (C) 1996 Elsevier Science Limited
\end{abstract}

Keywords: Poly(vinyl alcohol) membrane, artificial islet, diffusion, glucose, insulin

Received 26 October 1995; accepted 3 March 1996

Since the development of an asymmetric type of membrane by Loeb and Sourirajan ${ }^{1}$, the field of membrane science and technology has experienced an increasing growth. From the technological point of view, the most important properties of membranes are their functional properties such as permeability and permselectivity. For example, many techniques have been used to combine membrane technology with biological cells to treat a specific disease such as artificial pancreas ${ }^{2-11}$. The membrane is permeable to small molecules such as glucose or insulin but totally impermeable to large molecules such as antibodies and lymphocytes. Therefore, it is necessary to prepare membranes of proper structure to meet the requirements of its application.

Reported publications on the artificial pancreas using commercially available membranes limited their performance. Therefore, the aim of this work was to synthesize a series of asymmetric poly(vinyl alcohol) membranes, evaluate their permeability to glucose, vitamin B12 and insulin and to examine whether they could prevent the passage of immunoglobulin $G$. Furthermore, we examined the insulin secretory response of islets separated by a poly(vinyl alcohol) membrane.

Correspondence to Dr Tai-Horng Young.
Asymmetric membranes are produced by the so-called 'phase inversion' technique ${ }^{12}$. In this process, a casting solution consisting of polymer and solvent is immersed into a non-solvent coagulation bath. A solvent/nonsolvent diffusional interchange causes the casting solution to bring about phase transition, which forms the membrane. It has been suggested that the membrane formation process can be considered as a two-step mechanical model ${ }^{13}$. The membrane is divided into two layers: top-layer (or skin layer) and sub-layer. With the casting solution immersed into the coagulation bath, the top-layer is formed first at the casting solution-nonsolvent interface. Since solvent diffuses out very rapidly, the casting solution forms a dense skin layer. The dense layer will increase the barrier for diffusion of solvent from the sub-layer of casting solution. Therefore, when non-solvent diffuses into the sub-layer of casting solution, the composition of the sub-layer does not change and the sub-layer will proceed to liquid-liquid demixing to form a porous structure ${ }^{13}$.

\section{MATERIALS AND METHODS}

\section{Membrane preparation}

Poly(vinyl alcohol) was kindly supplied by Chang Chun Co. (Taiwan). The average molecular weight of 
poly(vinyl alcohol) used was about 74000 . Poly(vinyl alcohol) was dissolved in water to form a $14 \mathrm{wt} \%$ polymer solution at $90^{\circ} \mathrm{C}$. A series of different molecular weight polyethylene glycols were added to $50 \mathrm{~g}$ of polymer solutions, as shown in Table 1. Polyethylene glycols \#4000 and \#2000 were purchased from Nacalai Tesque (Kyoto, Japan) with the average molecular weight being about 4000 and 2000 , respectively. In poly(vinyl alcohol) membrane formation, polyethylene glycol was used as the pore former ${ }^{14}$ to increase the porosity and permeability of membranes.

The casting solution was kept at $25^{\circ} \mathrm{C}$ for $24 \mathrm{~h}$ and spread on a glass plate to a uniform thickness of about $100 \mu \mathrm{m}$ by an autocoater, which was immediately immersed into a coagulation bath with $\mathrm{Na}_{2} \mathrm{SO}_{4} / \mathrm{KOH} / \mathrm{H}_{2} \mathrm{O}=$ saturate/75 g/ $1000 \mathrm{ml}^{15}$ for $30 \mathrm{~min}$ to obtain a uniform membrane. The morphology of the membranes was examined using a scanning electron microscope (SEM).

\section{Permeability measurements}

The ability of poly(vinyl alcohol) membranes to allow diffusion of glucose, vitamin B12 and insulin (with a nominal activity of $28 \mathrm{IU} / \mathrm{mg}$; Sigma) were studied at $37^{\circ} \mathrm{C}$. Glucose and vitamin B12 concentration were characterized using a glucose analyser and spectrophotometer, respectively. Insulin concentration was determined by radioimmunoassay ${ }^{16}$. The permeabilities were measured using a two-chamber, well-stirred diffusion cell with a volume of $3.5 \mathrm{ml}$ in each chamber. The membrane was placed between two chambers with $0.64 \mathrm{~cm}^{2}$ of available membrane area. The stirring speed in each chamber was maintained at approximately $600 \mathrm{rpm}$ using independently controlled motors. Since the permeability measurement was performed under sufficient stirring, the diffusion resistance at the liquidmembrane interface was neglected.

One of the diffusion chambers was filled with phosphate-buffered saline (PBS) $(\mathrm{pH}=7.4)$ containing the diffusion molecules and the other chamber was filled with PBS only. The diffusion of solutes through the membranes was monitored by periodically removing $50 \mu \mathrm{l}$ samples from both chambers and an equal volume of solute-free PBS was refilled to avoid errors arising from volume variation. The mass balance can be written as

$$
V \frac{\mathrm{d} C_{2}}{\mathrm{~d} t}=\frac{A}{L} D\left(C_{1}-C_{2}\right)
$$

where $C_{1}$ and $C_{2}$ are concentrations of the solute in the donor and receptor chambers, respectively, $A$ is the exposed membrane area, $L$ is the membrane thickness and $V$ is the chamber volume. Equation (1) can be solved by analytical integration to give

$$
\ln \left[\frac{\left(C_{1}-C_{2}\right)_{t}}{\left(C_{1}-C_{2}\right)_{0}}\right]=2 \frac{D A}{L V} t
$$

where $\left(C_{1}-C_{2}\right)$ is the solute concentration difference at times 0 and $t$. Linear regression analysis of the above equation gave the slope $2 D A / L V$, from which the mass transfer coefficient $(D / L)$ was calculated. Each experiment was performed in duplicate and the results were expressed as the mean of the two results.

\section{Islet isolation and in vitro test}

An in vitro test was carried out to test the insulin secretory activity of islets prevented by the poly(vinyl alcohol) membrane. Islets were prepared from male Wistar rats $(250-350 \mathrm{~g})$ by a modification of the method of Lacy and Kostianovski ${ }^{17}$. The in vitro test used the same diffusion cell to evaluate the performance of poly(vinyl alcohol) membranes for the artificial islets. One of the diffusion chambers was filled with RPMI-1460 medium $(\mathrm{pH}=7.4)$ containing $500 \mathrm{mg} / \mathrm{dl}$ of glucose (glucose-side) and the other chamber was filled with glucose-free RPMI-1460 and about 200 rat islets of Langerhans (islet-side). The medium of both sides was sampled $(125 \mu \mathrm{l})$ periodically to analyse the variation in concentration of glucose and insulin, and an equal volume of medium was refilled.

\section{Immunoglobulin G (IgG) permeability test}

An IgG permeability test used the same diffusion cell. One of the diffusion chambers was filled with PBS $(\mathrm{pH}=7.4)$, while the other chamber was filled with fresh serum. Blood from healthy donors was allowed to coagulate for $30 \mathrm{~min}$ at room temperature. After centrifugation, serum was collected. IgG was monitored by removing $100 \mu \mathrm{l}$ samples until $100 \mathrm{~h}$ and was determined from fluorescence intensity.

\section{RESULTS AND DISCUSSION}

The permeation characteristics of the membranes are summarized in Table 1. The mass transfer coefficient in a given membrane decreased as the size of the diffusing molecules increased. Figure 1 shows, for instance, the diffusion curves of glucose through membranes 1-4. It was seen that good linear dependence was obtained for other permeability

Table 1 Effect of pore former on mass transfer coefficients of glucose, vitamin B12 and insulin through poly(vinyl alcohol) membranes

\begin{tabular}{lllll}
\hline $\begin{array}{l}\text { Membrane } \\
\text { no. }\end{array}$ & $\begin{array}{l}\text { Pore former }(\mathrm{g}) \\
\text { (Polyethylene glycol) }\end{array}$ & $\begin{array}{l}\text { Glucose } \\
(\mathrm{cm} / \mathrm{sec}) \times 10^{-4}\end{array}$ & $\begin{array}{l}\text { Vitamin B12 } \\
(\mathrm{cm} / \mathrm{sec}) \times 10^{-5}\end{array}$ & $\begin{array}{l}\text { Insulin } \\
(\mathrm{cm} / \mathrm{sec}) \times 10^{-6}\end{array}$ \\
\hline 1 & 0 & 1.06 & 2.84 & 1.45 \\
2 & $0.5(\# 4000)$ & 1.69 & 5.75 & 2.10 \\
3 & $1.0(\# 4000)$ & 1.98 & 5.91 & 3.76 \\
4 & $1.5(\# 4000)$ & 2.16 & 8.36 & 4.15 \\
5 & $0.5(\# 2000)$ & 1.28 & 2.95 & 1.89 \\
6 & $1.0(\# 2000)$ & 1.39 & 3.49 & 2.17 \\
7 & $1.5(\# 2000)$ & 2.03 & 5.10 & 3.16 \\
\hline
\end{tabular}




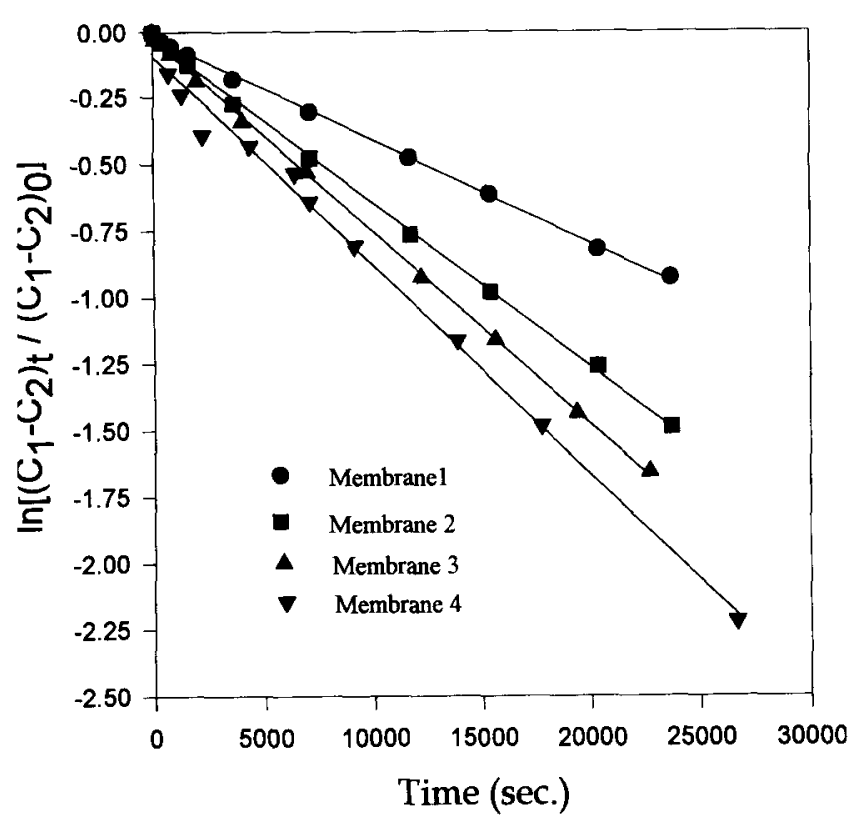

Figure 1 The diffusion curves of glucose through membranes 1-4.

measurements (not shown). In addition, it was found that the mass transfer coefficient of all the diffusion molecules increased with an increase of polyethylene glycol in the casting solution and the effect of PEG $\# 4000$ was greater than PEG \#2000. In order to investigate these permeation characteristics, the structure of membranes was examined by SEM. As shown in Figures 2-5, membranes 1-4 had a typical asymmetric structure: a thin skin layer supported by a porous sublayer. Membranes 5-7 also had the same structure (not shown).

Membrane 1 without polyethylene glycol in the casting solution showed a dense skin layer almost without any pores (Figure 2). From Figures 3(b), 4(b) and $5(b)$, however, it was evident that the pores in the skin layer increased with increasing amount of polyethylene glycol in the casting solution. The effect of polyethylene glycol on forming pores in the skin layer was attributed to the fact that water is a good solvent for polyethylene glycol. Therefore, as soon as the casting solution was immersed into the coagulation bath, polyethylene glycol near the surface was dissolved in the coagulation bath. Nevertheless, most of the polyethylene glycols were still embedded in the interior when membrane was formed. As a result, the structure of the outermost top layer was relatively dense. If the incipient membrane continued to be kept in the coagulation bath for a longer period, water could diffuse through the outermost top layer. Consequently, polyethylene glycols were released with a dissolutiondiffusion mechanism and they created pores which were originally occupied by polyethylene glycols in the incipient membrane. Therefore, the top-layer of membranes 3 and 4 could be considered as consisting of two parts: the outermost dense layer and a layer full of pores. In other words, the 'true' skin layer became thinner. It was implied that the permeation characteristics were greatly affected by the amount of polyethylene glycol in the casting solution, due to the principal diffusion resistance in the 'true' skin layer.
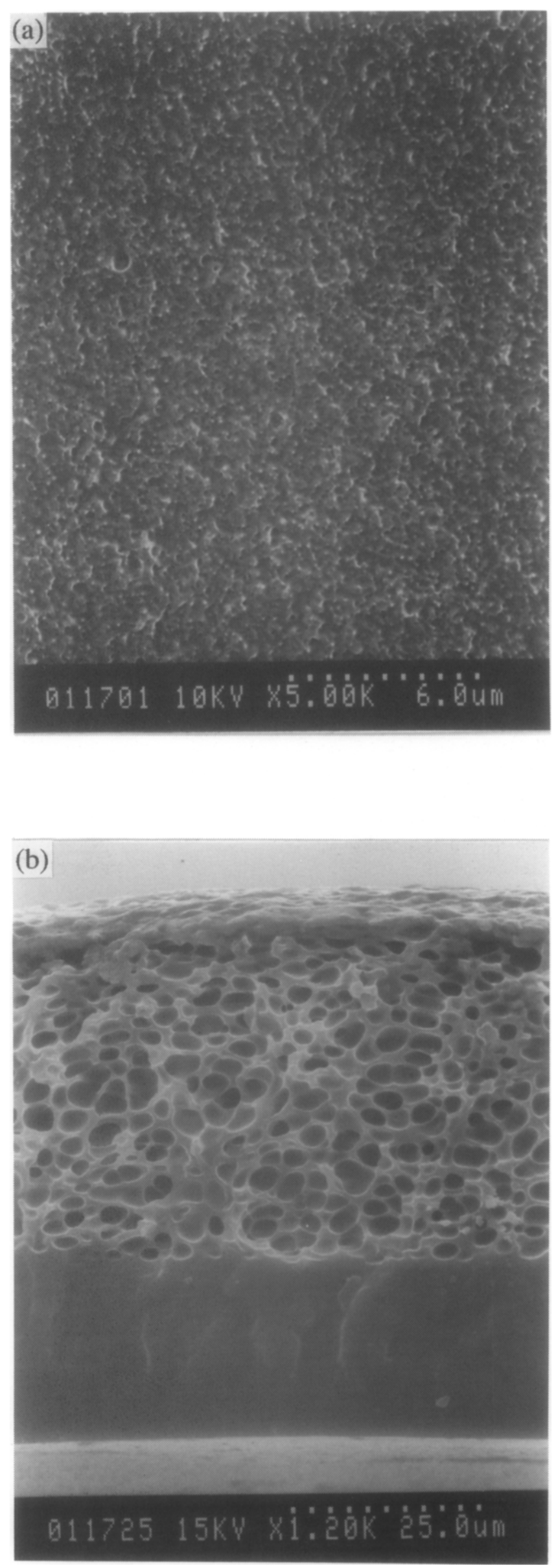

Figure 2 SEM pictures of membrane 1, a, Top; b, crosssection. 

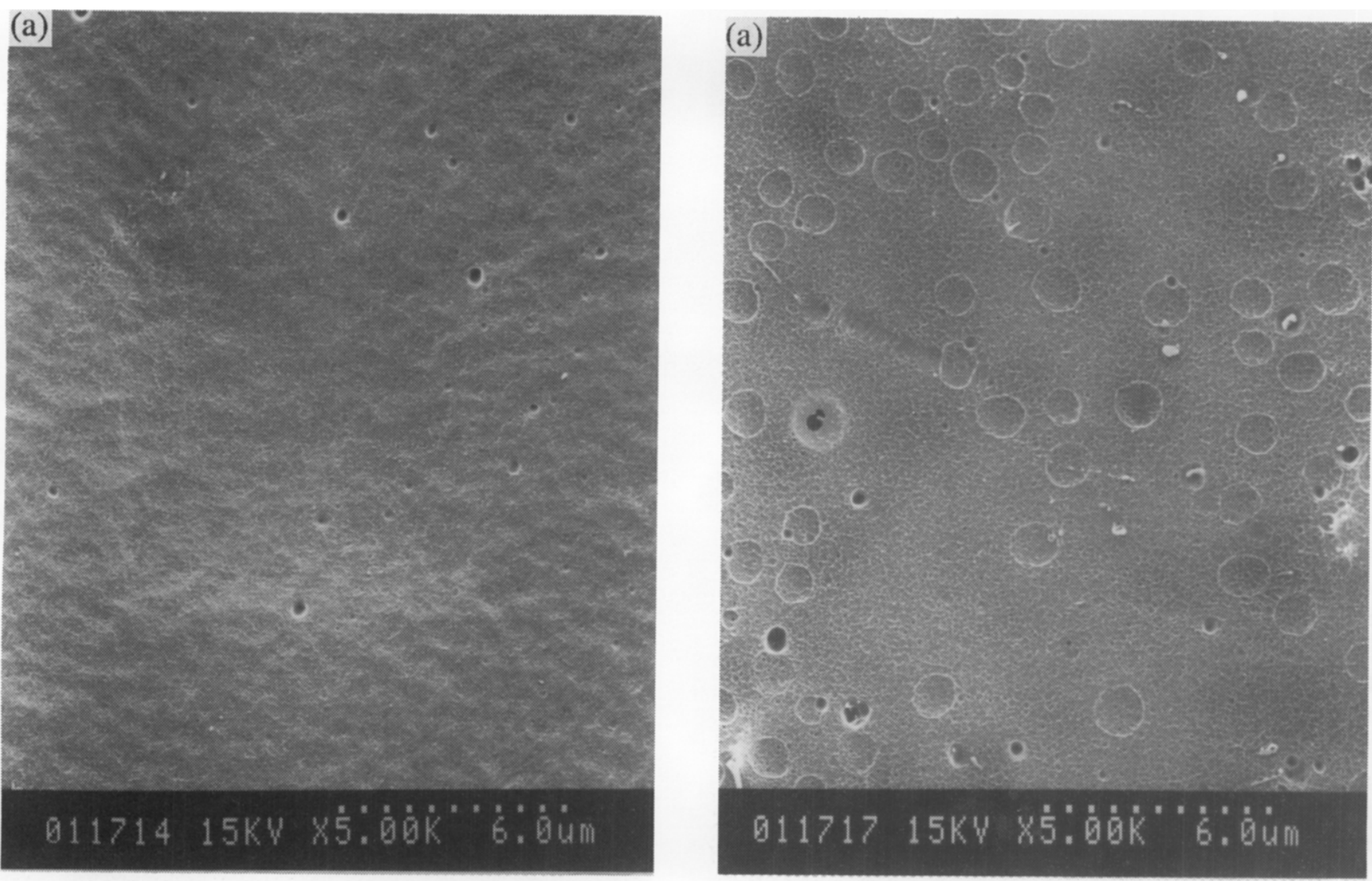

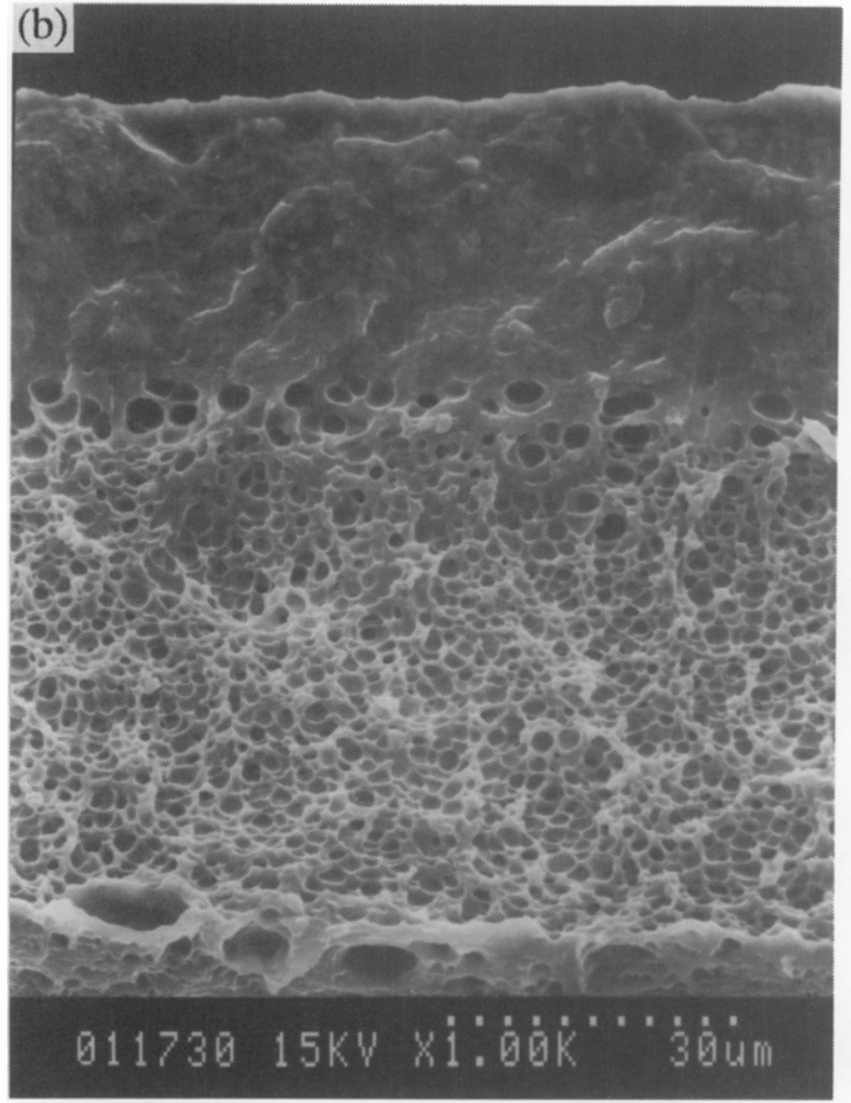

Figure 3 SEM pictures of membrane 2. a, Top; b, crosssection.

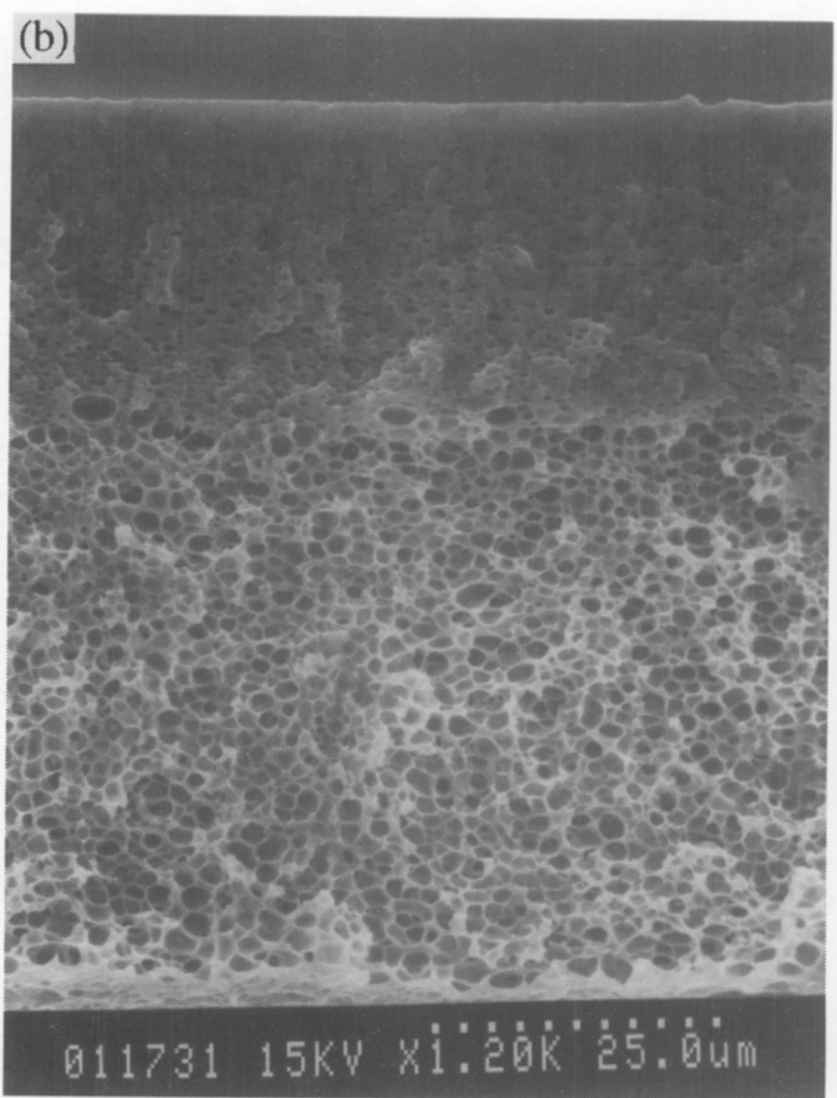

Figure 4 SEM pictures of membrane 3. a, Top; b, crosssection. 

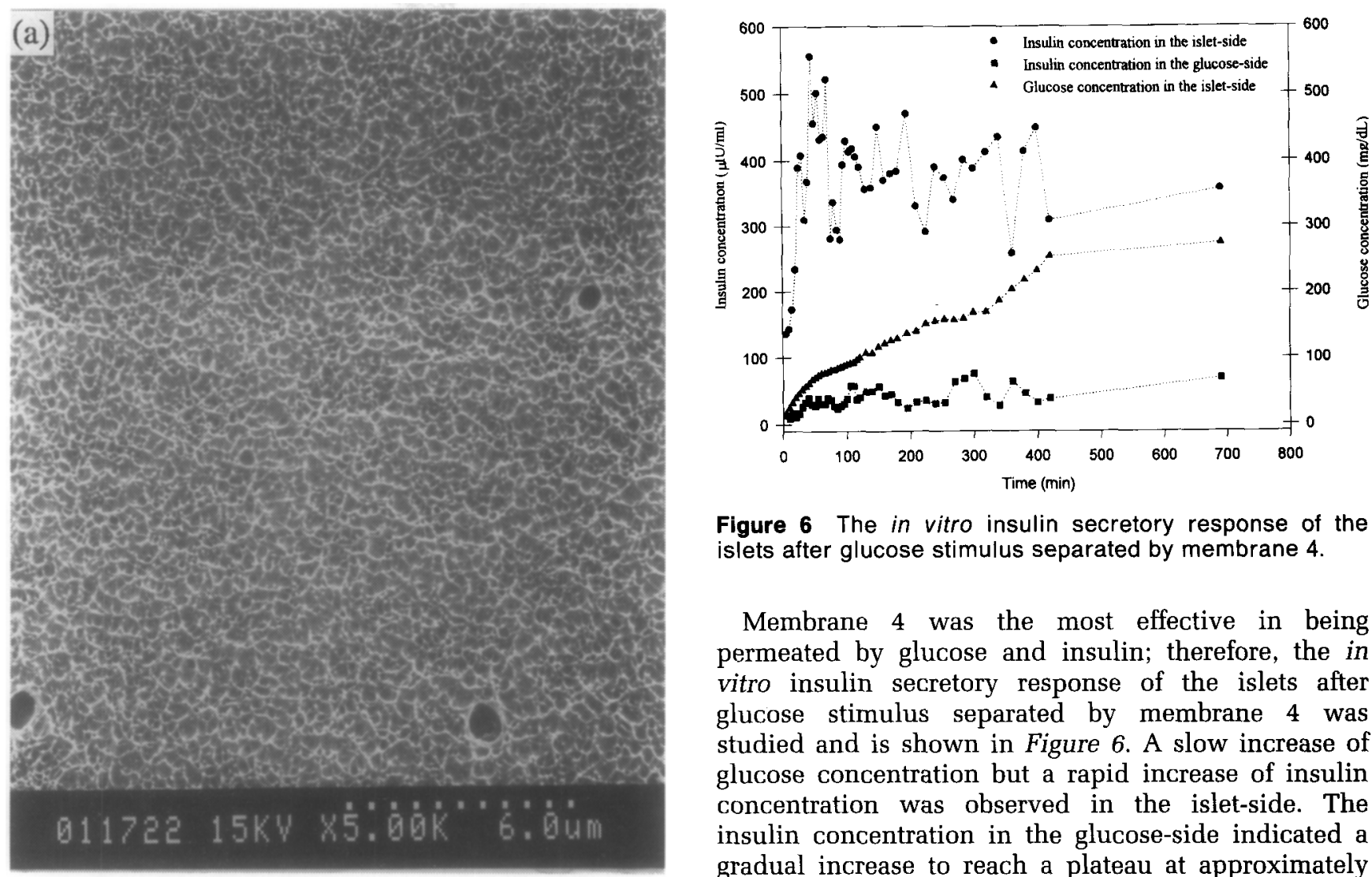

Figure 6 The in vitro insulin secretory response of the islets after glucose stimulus separated by membrane 4 .

Membrane 4 was the most effective in being permeated by glucose and insulin; therefore, the in vitro insulin secretory response of the islets after glucose stimulus separated by membrane 4 was studied and is shown in Figure 6. A slow increase of glucose concentration but a rapid increase of insulin concentration was observed in the islet-side. The insulin concentration in the glucose-side indicated a gradual increase to reach a plateau at approximately $30 \mathrm{~min}$. This finding indicated that the islets prevented by membrane 4 could respond to a glucose stimulus and secrete insulin. As shown in Figure 7, the artificial islet system could be considered with the aid of control theory as a dynamic model which combined three systems in series:

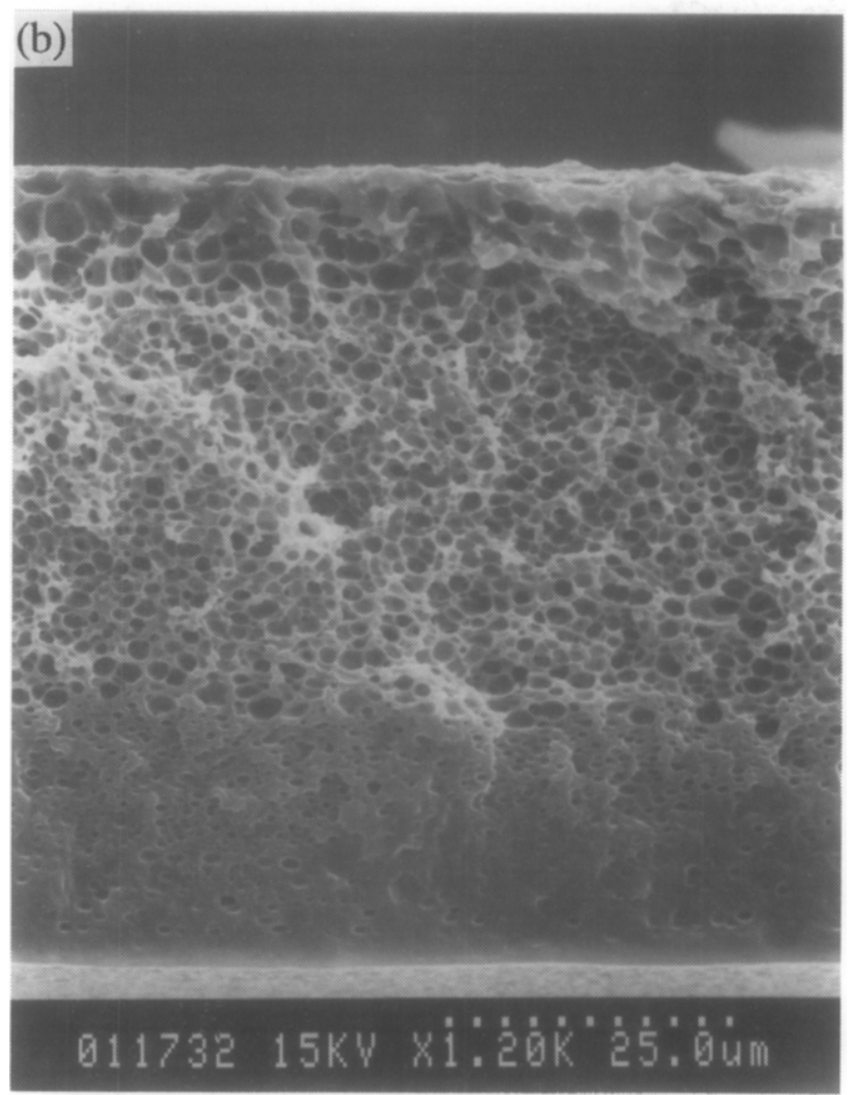

Figure 5 SEM pictures of membrane 4. a, Top; b, crosssection.
System 1: diffusion of glucose from the glucose-side through the membrane to the islet-side.

System 2: secretion of insulin by islets.

System 3: diffusion of insulin from the islet-side through the membrane back to the glucose-side.

The islet system could be regarded as an independent unit. Several insulin-secretion models are available ${ }^{18-20}$. From Figure 6, the glucose concentration rise of the islet-side was gradual, like a ramp input process for system 2. However, significant insulin-secretion occurred, and then gradually moderated. This indicated that brief exposure of the islets to glucose induces a rapid release of insulin and with continuous glucose

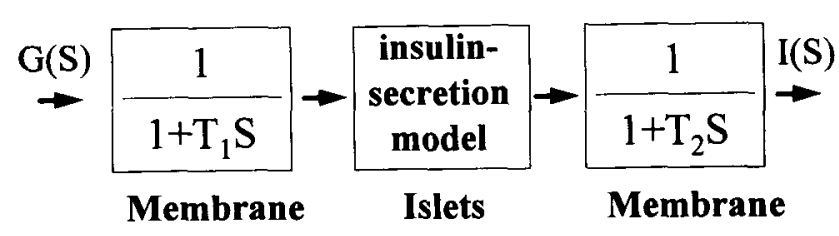

$T_{1}$ : time constant for diffusion of glucose

$T_{2}$ : time constant for diffusion of insulin

$\mathrm{G}(\mathrm{S})$ : glucose input

I(S): insulin output

Figure 7 Block diagram of the artificial islet model. 
exposure, the initial response fades, corresponding to the second phase insulin secretion ${ }^{21}$.

Using the Laplace transformation, Equation (1) can be expressed as

$$
\frac{C_{1}(S)}{C_{1}(S)}=\frac{1}{1+T S}
$$

$T$ indicating the time constant $(T=L V / A D)$. For systems 1 and 3 , the time constant was calculated to be about $420 \mathrm{~min}$ and $22000 \mathrm{~min}$ for diffusion of glucose and insulin through membrane 4, respectively. Both of these values are much greater than the time constant of the islets, $12 \mathrm{~min}$, proposed by Nomura et $a l^{20}$. Since diffusion and insulinsecretion processes were involved in the overall process, the relative rate was important. Therefore, when the insulin-secretion rate was relatively high compared to the rate of diffusion, the process was said to be diffusion-controlled. In addition, diffusion of glucose was faster than that of insulin; thus, the process is insulin-diffusion-controlled. Hence, it would be possible to obtain a less dense skin layer to increase the mass transfer coefficient of insulin to reduce the time lag of the artificial islets; however, the less dense structure may lead to the passage of antibodies and immune cells. Therefore, it was important to investigate whether the structure of poly(vinyl alcohol) membranes, in particular the outermost dense layer, was totally impermeable to larger molecules such as IgG. In our studies, no permeation of IgG through the poly(vinyl alcohol) membranes 1-7 could be detected within the experimental time frame. Theoretically such membranes, thus, could completely avoid the permeation of antibodies and immune cells.

\section{CONCLUSIONS}

To ensure the rapid response of islets prevented by an artificial membrane, the membrane should have high permeability for glucose and insulin. Although low permeability of poly(vinyl alcohol) membrane to insulin was an obstacle to the artificial islets, we had proposed modifying the properties of the skin layer to improve insulin permeation. Adding polyethylene glycols to the poly(vinyl alcohol) membrane formation system, phase inversion process occurred first to determine the membrane structure with a dense skin layer supported by a porous sub-layer. Subsequently, polyethylene glycols were released to create pores in the skin layer. Since the 'true' skin layer became thinner by increasing the amount or molecular weight of polyethylene glycol in the casting solution, it was possible to obtain poly(vinyl alcohol) membranes with quite precisely identified permeation properties. This study clearly showed the effect of the structure of the skin layer on the permeation characteristics of the membranes. Furthermore, the size difference among the penetrant molecules in the artificial islets is quite large, so the 'true' skin layer could still function adequately as an immunoprotective barrier. These preliminary data were consistent with the potential interest for the development of artificial islets.

\section{ACKNOWLEDGEMENTS}

The authors thank the National Science Council of the Republic of China for their financial support by project NSC 84-2331-B-002-156-M08.

\section{REFERENCES}

1 Loeb S, Sourirajan S. Sea water demineralization by means of an osmotic membrane. Adv Chem Ser 1963; 38: 117.

2 Lim F, Sun AM. Microencapsulated islets as bioartificial endocrine pancreas. Science 1980; 210: 908910.

3 Altman JJ, Houlbert A, Callard, P, McMillan P, Solomon BA, Rosen J, Galetti PM. Long term plasma glucose normalization in experimental diabetic rats with macroencapsulated implants of benign human insulinomas. Diabetes 1986; 35: 625-633.

4 Inoue K, Fujisato T, Gu YJ, Burczak K, Sumi, S, Kogire M, Tobe T, Uchida K, Nakai I, Maetani S, Ikada Y. Experimental hybrid islet transplantation: application of polyvinyl membrane for entrapment islets. Pancreas 1992; 7: 562-568.

5 Burczak K, Fujisato T, Hatadaand M, Ikada Y. Protein permeation through poly(vinyl alcohol) hydrogel membranes. Biomaterials 1994; 15: 231-237.

6 Lanza RP, Beyer AM, Chick WL. Xenogenic humoral responses to islets transplated in biohybrid diffusion chambers. Transplantation 1994; 57: 1371-1375.

7 Ward RS, White KA, Wolcott CA, Wang AY, Kuhn RW, Taylor JE, John JK. Development of a hybrid artificial pancreas with a dense polyurethane membrane. ASAIO J 1993; 39: M261-267.

8 Kessler L, Pinget M, Aprahamian M, Poinsot D, Keipes $M$, Damge C. Diffusion properties of an artificial membrane used for Langerhans islets encapsulation: interest of an in vitro test. Transplant Proc 1992; 24: 953-954.

9 Zekorn T, Bretzel RG, Siebers U, Doppl W, Renardy M, Zschocke P, Planck H, Federlin K. Protein coat causes improved insulin diffusion through membranes for immunoisolated islet transplantation. Improved islet survival by pretreatment of membrane and islets. Transplant Proc 1990; 22: 867-869.

10 Kessler L, Aprahamian M, Keipes M, Damge C, Pinget $M$, Poinsot D. Diffusion properties of an artificial membrane used for Langerhans islets encapsulation: an in vitro test. Biomaterials 1992; 13: 44-49.

11 Kessler L, Legeay G, Jesser C, Damge C, Pinget M. Influence of corona surface treatment on the properties of an artificial membrane used for Langerhans islets encapsulation: permeability and biocompatibility studies. Biomaterials 1995; 16: 185-191.

12 Kesting RE. Synthetic Polymeric Membranes. New York, NY: John Wiley and Sons, 1985.

13 Young TH, Chen LW. A two step mechanism of diffusion controlled ethylene vinyl alcohol membrane formation. J Membrane Sci 1991; 57: 69-81.

14 Sakurada Y, Sueoka A, Kawahashi M. Blood purification device using membranes derived from poly(vinyl alcohol) and copolymer of ethylene and vinyl alcohol. Polymer J 1987; 19: 501-513.

15 Sakurada I. Polyvinyl Alcohol Fibers. New York and Basel: Marcel Dekker, 1985.

16 Hsu CH, Hong TH, Yin KW. Purification of radioiodinated human insulin by high performance liquid 
chromatography for a sensitive radioimmunoassay. I Formosan Med Assoc 1992; 91: 9-14.

17 Lacy PE, Kostianovski, M. Method for the isolation of intact islets of Langerhans from the rat pancreas. Diabetes 1967; 16: 35-39.

18 Grodsky GM. A threshold distribution hypothesis for packet storage of insulin and its mathematical modeling. J Clin Invest 1972; 51: 2047-2059.

19 Cerasi E, Frick G, Reedemo M. A mathematical model for the glucose induced insulin release in man. Eur $J$ Clin Invest 1974; 4: 267-278.

20 Nomura M, Shichiri M, Kawamori R, Yamasaki Y, Iwama $\mathrm{N}$, Abe $\mathrm{H}$. A mathematical insulin-secretion model and its validation in isolated rat pancreatic islets perifusion. Comp Biomed Res 1984; 17: 570579.

21 Genuth SM, Berne RM, Levy MN, eds. Principles of Physiology. Wolfe Publishing, 1990. 